\title{
A Comprehensive Survey on Node Metrics of RPL Protocol for IoT
}

\author{
Adeeb Saaidah ${ }^{1}$, Omar Almomani ${ }^{1}$, Laila Al-Qaisi. ${ }^{1}$, Nesreen Alsharman ${ }^{1} \&$ Faisal Alzyoud $^{2}$ \\ ${ }^{1}$ Faculty of Information Technology, The World Islamic Sciences \& Education University Amman, Jordan \\ ${ }^{2}$ Faculty of Information Technology, Isra University, Amman, Jordan \\ Correspondence: Omar Al-Momani, Faculty of Information Technology, The World Islamic Sciences \& \\ Education University Amman, Jordan. E-mail: omar.almomani@wise.edu.jo
}

Received: October 10, 2019

Accepted: October 26, 2019

Online Published: November 5, 2019

doi:10.5539/mas.v13n12p1

URL: https://doi.org/10.5539/mas.v13n12p1

\begin{abstract}
Internet of Things (IOT) system often consists of thousands of constrained connected devices. Resource-constrained devices one of critical issues in a low- power and lossy network LLNs. RPL is IPv6 routing protocol. It's designed by IETF to be simple and inter-operable networking protocol to overcome these resource limitations. The RPL carries out Objective Functions (OFs) in the aim of finding the best path. The OFs chooses the best parent nodes aiming to build the route and optimize it. The metrics used to build the OF must be selected in an effective and accurate manner for finding the optimal path and meets all constraints. A survey about node metrics which can be utilized in OFs of RPL is presented, and node metrics calculations are explained then discussed thoroughly. The researcher displays the most relevant research efforts regarding the RPL OFs existing in literature.
\end{abstract}

Keywords: internet of things (IOT), RPL, LLNs

\section{Introduction}

Regarding LLNs, it consists from huge number of connected devices by lossy links. These links work only on data rates that are low (Saaidah et al. 2019). These devices have limited resources along with constraint in memory, processing power, processing capability, transmission range and battery lifetime (Saaidah et al. 2019). Different domains are supported by LLN such as home, building automation, health and industrial (Kamgueu et al. 2018; Kharrufa et al. 2019). The development of using LLN in different domains imposes us to find solution for constraints that are attached to devices in LLNs. So, special requirements are needed to handle this situation. These requirements are considered different from traditional wired networks. They are considered different from the requirements of wireless ad hoc networks as well. The traditional networks concern is limited support to traffic, scalability, network dynamicity, latency, manageability, convergence time stability, and support to mobility (Lamaazi et al. 2016). In order to cover this limitation, a routing protocol has been proposed by the roll working group as a tree. This routing protocol of LLN is RPL (Lamaazi et al. 2016; Saaidah et al. 2019).

RPL support different communication mechanisms, like the multipoint-to-point communications and the point-to-point (Gaddour\&Koubâa 2012; Kim et al. 2017). It only keeps an optimal routing at a time. Moreover, it just selects one of the parent nodes that are considered to be the best among the rest (Lamaazi\&Benamar 2018; Saaidah et al. 2019). The OFs seeks choosing and optimizing the route that is between nodes. It seeks deciding which node can join the destination in accordance with specific metrics, like: the delay, power, number of expected transmission, hop count (HC), link quality level (Gaddour et al. 2014). RPL aims at building a Destination Oriented Directed Acyclic Graph (DODAG) in accordance with a group of constraints and metrics. That is done through carrying specific OFs (Gaddour et al. 2014; Sankar\& Srinivasan 2017). The metrics that shall be used for defining the best path was not defined by the working group and left flexible. Which enables it to meet the requirements of the application and network designs. Figure 1. Displays the Downwards and Upwards routs DODAG of basic operation for RPL. 


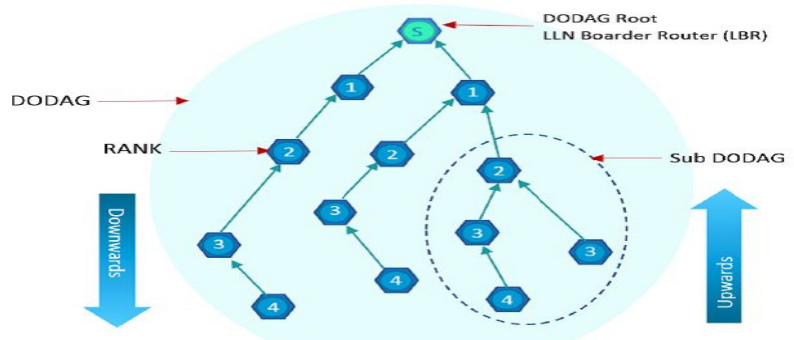

Figure 1. Upwards vs. Downwards routs DODAG

Many researches in the last years had an interest in studying RPL protocol by characterize, evaluate, and propose enhancements. These studies range from choosing the optimal parameter selection for specific applications and apply performance evaluation in different implementations and environments such as test-bed or simulations environments. Other studies such as (Kamgueu et al. 2013; Xiao et al. 2014; Aljarrah 2017) focusing on OFs node metrics, while other (Rehman et al. 2016; Ji et al. 2018)focused on link metrics and others (Nurmio et al. 2015; Shakya et al. 2017; Lamaazi \& Benamar 2019) combine both node and link metrics. Choosing the metrics should be taken accurately due to the RPL rely on that to choose the optimal path. So, we should understand each metric to be used in suitable way to get the result that serves the requirements in any system.

Node metrics play a significant role to choose the optimal path for LLN. Existing node metric can be divided broadly into six categories as shown in Figure.2, namely; Node state and attributes object, Hop count (HC), Node energy, Number of connected neighbor, and Maximum Lifetime (MLT) . Node state and attributes object can be further classified into Congestion flag, CPU usage and Available memory energy. Node energy can also be classified into Energy consumption (EC), Remaining Energy (RE) and Battery discharge index. EC is classified into CPU power consumption, Power consumption during low power mode (LPM), Power consumption during transmission and Power consumption during listen.

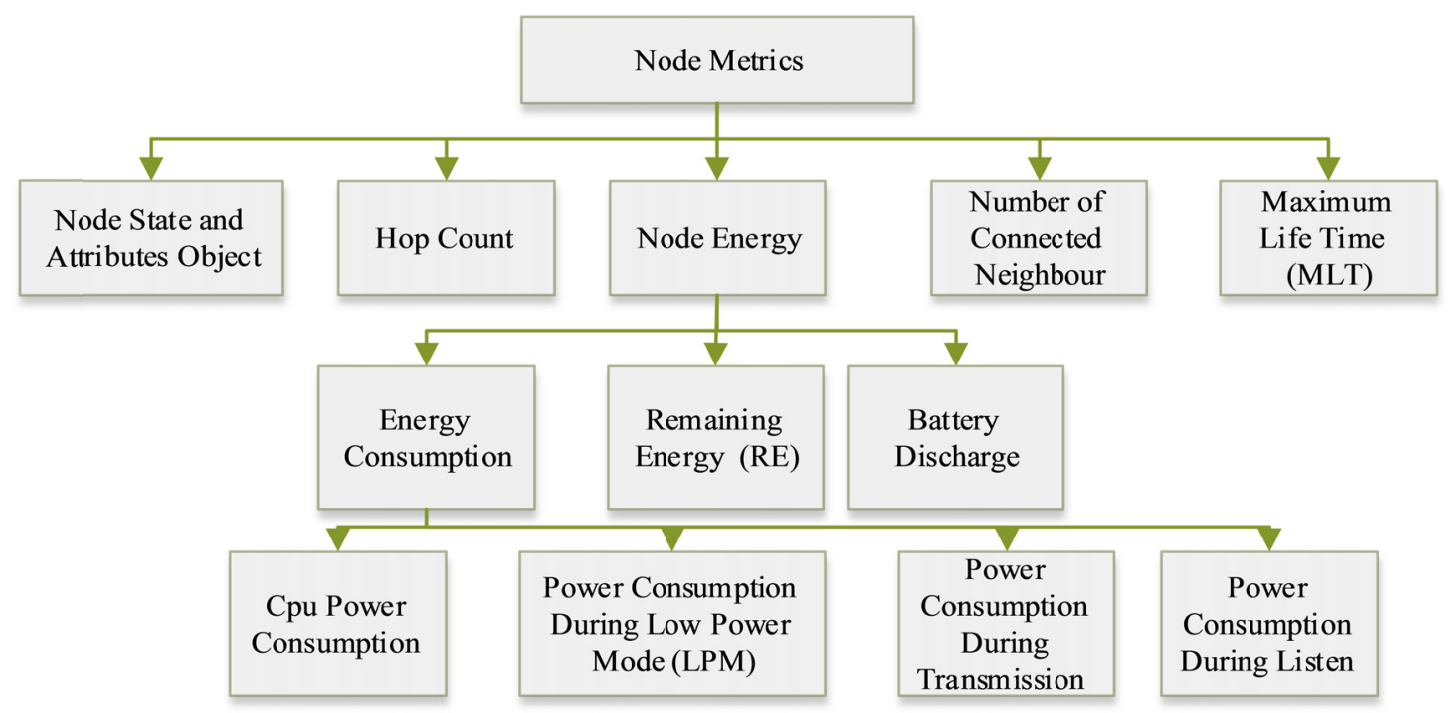

Figure 2. Node metrics classification

Searching through previously presented studies in literature about RPL OFs, no conducted survey has focused on node metrics of RPL OFs which led the researchers to conduct then write the present survey-based paper. This paper aims at discussing the primary efforts exerted for improving the RPL OF based on node metric.

Following sections of this study are organized as follows: Section II presents scope of survey. Section III is explaining the RPL protocol. In section IV discussion of approaches used to combine metrics is presented. Section V displays a survey of node metrics. Section VI presents a comparison between RPL OFs Finally, in Section VII summarizes conclusion of the survey paper.

\section{Scope of Study}

In this study, a review of the previous studies targeting RPL OF's enhancement-based node metric is presented. An analysis of the currently existing mechanisms based on node metrics for selecting optimal path and its 
implementations for single metric and combine metrics are listed then summarized. The contributions of this survey paper are as follows:

- Provide a background on RPL protocol.

- Discuss composition approaches used for node metrics.

- Explain calculations of each node metrics.

- Comparative study of RPL OFs based on node metrics is presented.

\section{RPL Overview}

A routing protocol is used to transfer the packets to nodes. In WSN the routing protocol is classified to Reactive and Proactive. The reactive protocols like AODV (Al Balas et al. 2019), DSR (Johnson et al. 2001) and TORA (Sharma \& Kumar 2016), set routes when needed only. Therefore, the node doesn't need to start a route discovery process. Thus, reactive protocols produce higher latency and lower overhead. Whilst the proactive routing protocols set the routes before it need any data and every node maintains routing tables that representing the network topology. Therefore, these protocols need to update routing table periodically. Nodes send two kinds of messages, namely; the control messages for neighborhood information and data messages for information among all the nodes.

RPL is distance vector protocol and a proactive routing protocol (Dong \& Li 2019). It starts finding the routes when RPL network is initialized. RPL is a form of tree topology named DAG (Charles \&Palanisamy 2018). Every RPL node has a preferred parent node that plays like a sink for that node. The nodes in RPL network possess routes for all the nodes down its tree. Path route selection is a very important part of RPL, because it uses different matrices to compute best paths (rank). Selecting best path in RPL mainly depend on node metrics, such as: Node Energy and HC, Node State Attribute (NSA). It may depend on link metrics, such as: Throughput, Latency, Link Quality Level, ETX and Link Color or combined node and link metrics (Gaddour et al. 2014; Sankar\& Srinivasan 2017).

The RPL protocol has four kinds of control messages for making network maintenance and exchanging information (Aissa et al. 2019). The first kind is named DODAG Information Object (DIO), this kind consider the fundamental source of routing control information. It seeks storing information about current RPL Instance, current rank and the root's address. The second kind is named a Destination Advertisement Object (DAO). It supports down traffic and it's employed for propagating the destination information upwards along the DODAG. The third kind is named DODAG Information Solicitation (DIS), It allows the node to require DIO messages from a neighbor that's reachable. The forth kind is a DAO-ACK, It's sent by a DAO recipient and it's sent in response to a DAO message. All of these kinds of control messages in RPL are named ICMPv6 (Gaddour\&Koubâa 2012; Kim et al. 2017; Bisen\& Matthew 2018). Figure. 3 display basic RPL tree topology.

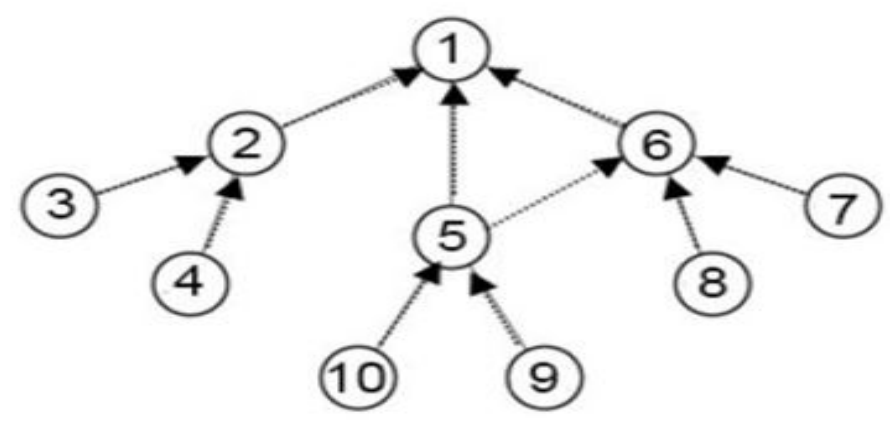

Figure 3. RPL Tree Topology

\section{Metrics Composition Techniques}

The composition techniques used to combine more than one metric can be classified into three techniques namely, lexical, additive and fuzzy logic.

\subsection{Lexical Metric}

This composition provides a preference between two metrics by comparing them and it is not compulsory for metrics to have same relation. The first component metrics that provide high or low value according to the routing characteristic it shall be chosen as being the best parent toward the root. If the first component has equal 
values, the node shall check the second component. The latter component shall determine the DODAG parent (Karkazis et al. 2012).

\subsection{Additive Metric}

This composition is about combining multiple metrics with the same order relation. Additive composition is combining multiple metrics to produce one output metric and then DIO messages is used to advertise output metric.

\subsection{Fuzzy Logic}

Fuzzy logic is part of computational intelligence. It's a popular research area that deals with processing numerical data (Michael 2005; Negnevitsky 2005; Ingoley \& Nashipudi 2012). Fuzzy logic is defined as the encoding of facts using mathematical expressions with relevant membership values (Rossides et al. 2002; Abdel-Jaber \& Mahafzah 2008). Fuzzy logic used to convert many linguistics input variables into one output variable by using Fuzzy Inference Process (FIP). FIP defined as "a processes carried out for mapping from a specific input to an output through employing the fuzzy sets theory" (Mamdani \& Assilian 1975; Gottwald 2013). The Mamdani-style FIP is a fuzzy inference technique that's widely used in fuzzy logic. This FIP involves four primary steps (Mamdani \& Assilian 1975): fuzzificating inputs, evaluating rules, aggregating output rules, and defuzzificating as shown in Figure 4.

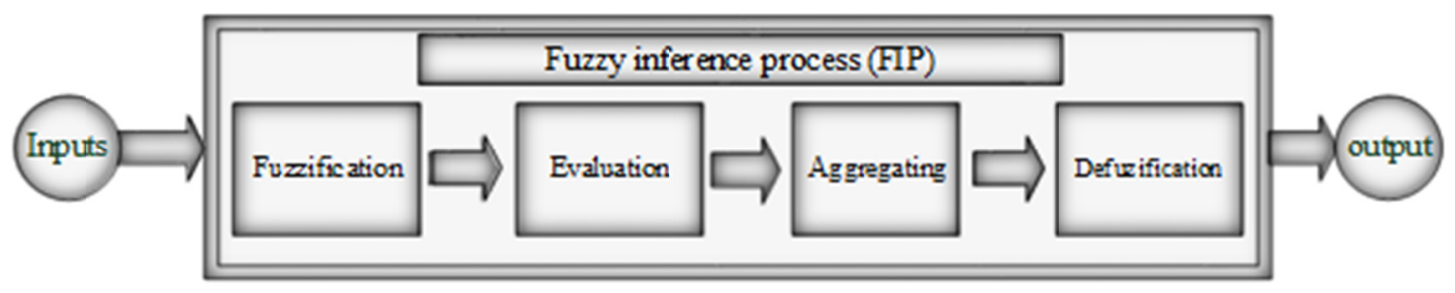

Figure 4. FIP process

\section{Node Metrics}

\subsection{Node State and Attributes Object}

The node state and attribute (NSA) object is usually employed for collecting information about a node (Ullah et al. 2017). The NSA object may be existent in the DAG. It may include a group of TLVs that is usually used for conveying several node characteristics. Currently, there isn't any TLV defined. The format of the latter object body as shown in Figure 5. (Ullah et al. 2017; Barthel et al. 2012):

\begin{tabular}{|c|c|c|c|c|c|c|c|c|c|c|c|c|c|c|c|c|c|c|c|c|c|c|c|}
\hline 0 & & & & & & & & & & 1 & & & & & & & & & & 2 & & & \\
\hline 0 & 1 & 2 & 3 & 4 & 5 & 6 & 7 & 8 & 9 & 0 & 1 & 2 & 3 & 4 & 5 & 6 & 7 & 8 & 9 & 0 & 1 & \begin{tabular}{l|l}
2 & 3
\end{tabular} & 4 \\
\hline & & & & & & & & & & & & & & A & $\mathrm{O}$ & & & & ק- & al 7 & LVs & & \\
\hline
\end{tabular}

Figure 5. NSA Object Body Format

Res flags are denoted for reserved field with 8 bits. They should be set to 0 on transmission and ignored on receipt. Flags field is eight bits. The following two bits of the NSA object are defined currently as: 'A 'flag: data Aggregation Attribute. Some applications may utilize the aggregation node attribute in their routing decision. That's done for minimizing the amount of traffic on the network. That may increase its lifetime in environments that are battery operated (Barthel et al. 2012; Ullah et al. 2017).

'O' flag: node workload may be hard to express and determine in some scalar form. However, node workload could be a useful metric to consider during path calculation, in particular when queuing delays must be minimized for highly sensitive traffic considering Medium Access Control (MAC) layer delay. The node may not be capable of processing traffic (Barthel et al. 2012; Ullah et al. 2017).

\subsection{Node Hop Count}

$\mathrm{HC}$ is a metric that represents number of intermediate nodes for reaching another node. Here the node to be reached is a parent node via which the data are transmitted to root. In best case the route with minimum number of hops results with minimum delay and higher link connectivity (Aljarrah 2017).

It is the metric employed for identifying the number of hops from source to destination. In Contiki operating system, the OF zero (OF0) is considered the default OF and chooses the path to the root that has the minimum number of hops (Lamaazi et al. 2016). Contiki employs a 16-bit rank value in units of 256 that allows a 
maximum of 255 hops. Each node shall calculate its rank with respect to its parent rank using the summation of the parent rank and the (default-min-hop-rank-increase) value that is defined as 256 in the RFC 6550. The rank calculation based on hop count OF may be calculated as it's displayed through equation 1(Abdel Hakeem et al. 2019).

$$
R(n)=R(P)+(\text { default_min_hop_rank_increase })
$$

While $\mathrm{R}(\mathrm{n})$ stands for the rank of the node $\mathrm{n}, \mathrm{R}(\mathrm{P})$ stands for the rank of the node parent and Node (n) chooses the parent node that shall minimize the value of $R(n)$.

ETX is defined as the expected number of transmissions which are required to send a packet over the communication link (Lamaazi \& Benamar 2018). The path ETX is the sum of the ETX of all the links along the path. When ETX is applied, the nodes must select the parent that has the lowest ETX value. Each node uses ETX to calculate the path to the root node and select its parent, which has the minimum overall ETX to the root node. ETX over a link can be calculated using equation 2(Abdel Hakeem et al. 2019):

$$
\mathrm{ETX}=1 /(\mathrm{DF} * \mathrm{DR})
$$

DF stands for how probable to receive a packet from the neighbor node.

DR stands for how probable to receive successfully an acknowledgment. Node (n) is capable of calculating its rank based on ETX using equation 3 (Abdel Hakeem et al. 2019)

$$
\mathrm{R}(\mathrm{n})=\mathrm{ETX}+\mathrm{R}(\mathrm{P})
$$

$\mathrm{R}(\mathrm{P})$ stands for the rank of the parent node, so the total node rank can be expressed as the rank of its parent with the addition to ETX of the total path.

\subsection{Node Energy}

The IoT is a new technology that involves a wide spectrum of applications that concerns smart metering, industrial control, home automation, e-Health, agriculture and others. In order for those applications to run in an autonomous manner, the IoT devices must survive for years under energy constraints that are strict. When developing such applications, it's very important for the applications to have knowledge about their EC.

The choice of metrics plays a big role in analyzing the performance of the OF through using the routing protocol. WSN has been used since a long time for supporting several applications (mainly the ones related to detection, monitoring and tracking). Regarding the Nodes in a WSN, they are resource constrained and battery powered (i.e. limited size of memory, communication and processing) (Culler et al. 2004). There isn't any cable attached for powering those devices. Therefore, they run on limited battery powered resources. It becomes a daunting challenge to power those devices. Energy is considered a significant metric. As it's supported to increase the lifetime of network (Aljarrah 2017). This means that the average energy measured from nodes in the network over the network lifetime (Lamaazi et al. 2018). So, the researchers categorized the node energy metric as follows: energy consumption, RE and battery.

Energy Consumption (EC)

EC refers to the energy of nodes that is spent during the exchange of information within the network (Lamaazi \& Benamar 2018). The EC of a node is significant for sensor networks. Therefore, powers saving techniques are needed to disable nodes for a temporary period in order to conserve energy.

Energy can be managed through assigning states to the nodes of a sensor network as receive, transmit, low power mode (LPM)which means idle sleep modes, LISTEN, CPU modes. Nodes are at transmitting state while transmitting a packet and in receive state while receiving a packet. A node consume power at idle state as it has to listen to the medium so that it can enter receives state if it detects a transmission. In sleep state, a node cannot transmit or receive any data. The node energy may be calculated from the summation of all states energy as it's presented in Equation 4 (Lamaazi \& Benamar 2018):

$$
\text { Node energy }=\text { ENG-TRANSMIT + ENG-LISTEN+ ENG-CPU + ENG- LPM. }
$$

CPU energy consumption: This represents the energy consumed by $\mathrm{CPU}$, it calculate using Equation 5

$$
\text { ENG-CPU }=(\text { CPU_time*1.8mA }) * \mathrm{Vcc} / 32768
$$

Where $1.8 \mathrm{~mA}$ represent the level of power consumption of nodes in CPU state which are expressed in milliamperes (mA).

Low power mode LPM power consumption: Energy consumed by the node in low power mode, it calculate using Equation 6: 
Where $0.0545 \mathrm{~mA}$ represent the level of power consumption of mote in CPU state which is expressed in milliamperes $(\mathrm{mA})$.

Transmition Energy consumed by the node DURING TRANSMITION, ,it calculate using Equation 7:

$$
\text { ENG-TRANSMIT }=\text { Transmit } * 19.5 \mathrm{~mA} \mathrm{Vcc} /(32768)
$$

listen power consumption: Energy consumed by the node DURING LISTEN, it calculate using Equation 8:

$$
\text { ENG-LISTEN }=\text { Listen } * 21.5 \mathrm{~mA} \mathrm{Vcc} \mathrm{/} \mathrm{(32768)}
$$

$0.0545 \mathrm{~mA}$ represent the level of power consumption of nodes in CPU state which is expressed in milliamperes (mA). In order to calculate the power consumption in milliwatt per seconds; we should multiply the total consumption by voltage and divide by the number of clock ticks per second which is RTIMER_SECOND Where the value of RTIMER represents the number of ticks per second which is equal to 32768 ticks per second that is used for measuring the processing time (measure the time duration of the nodes running on specific mode)(Patel 2008).Vcc represent node battery voltage which almost equal to $3 \mathrm{v}$ (Patel 2008; Information Resources Management Association 2015).

In (Shakya et al. 2017) proposed a new OF named Smart Energy Efficient-OF (SEEOF). It aimed to provide energy efficiency techniques and extend the network lifetime. SEEOF uses an additive combination of both ETX and EC. As a result, SEEOF improved the network lifetime by up to $27 \%$. In addition, it permits making the energy consumed by nodes more uniformly. That shall make them alive for long period of time. The SEEOF aims at improving the performance of RPL protocol. However, it was compared to the standard MRHOF only. That makes its efficiency unknown in comparison with candidate proposals.

In (Lamaazi \& Benamar 2018) authors proposed a new OF. That was done based on combined metrics through the use of Fuzzy Logic named (OF-EC). For overcoming the limitations of using a single metric and optimizing the route or for choosing the suitable path for nodes to reach destination, the proposed OF-EC considers the link metrics and the node metrics, namely the ETX, HC and EC. Thus, the proposed OF-EC allows equalizing the distribution of the EC of all nodes. That shall decrease the probability of having network failure and raise the lifetime of nodes. OF-EC compared with OF-ETX, ENTOT, and OFFUZZY. It was found that OF-EC provide more efficiency compared other even if the network topology and the transmission range change.

In (Sousa et al. 2017) proposed an OF to be used for IoT applications called Energy Efficient and Path Reliability Aware OF (ERAOF) to ensure efficient energy for reliable transmission of data. It is based on combining both energy and link routing quality metrics. ERAOF is based on two routing metrics, namely; energy consumed (EC) and ETX. In ERAOF, EC making the RPL aware of network EC and ETX plays a role to specify quality of link through network nodes. This leads to better performance by decreasing use of connections with less condition. Each network node will compute a value T(ni), which is quality of node (i) in terms of EC and ETX and the Equation 9 is used as follows:

$$
T(n i)=F E C(n i)+f E T X(n i, n j)
$$

Where, FEC(ni) represents the function which returns the energy consumed by the node i since the beginning of its operation. Then, in terms of EC and ETX quality of route $r$, is defined as Q(r), and its value is computed by the sum of $\mathrm{T}(\mathrm{ni})$ values of the nodes which compose it, as in Equation 10.

$$
Q(r)=\sum_{i=1}^{j} T(n i) \quad i, j, r \in N *
$$

The experiments' results showed that proposed OF kept effective EC with increasing the ratio of packet delivery and using less hops.

(Lamaazi \& Benamar 2019) proposed assessment approach for RPL performance using its own components. They have suggested using both OF and trickling algorithm. A comparative study was conducted between RPL-EC with OF depending on ETX and power consumption being combined through fuzzy logic, and RPL-FL using trickle algorithm that's flexible. Implementations of both suggested RPL-EC, RPL-FL along with the standard RPL were conducted to detect improvements of them. Five main measurements were chosen to assess the improvement, namely; overhead, convergence time, packet delivery ratio (PDR), EC, and the lifetime of network. It was found that OF and trickle algorithm has effect on RPL performance. RPL-EC has better values for convergence time and network lifetime in comparison with the standard RPL. On the other hand, RPL-FL given best values in terms of overhead, EC, PDR.

While in (Kamgueu et al. 2015) a two- phases employing fuzzy logic procedures was proposed to integrate three 
linguistic input variables called ETX, energy and delay. In the first phase, the ETX and delay were integrated for producing output variables call Quality of Service (QoS). Through the second phase, energy was integrated with the QoS value and fuzzy output is quality. The proposed fuzzy-logic is assessed in comparison to ETX-RPL based on a real testbed network consisting from twenty-eight sensor nodes. A comparison between ETX-RPL and proposed fuzzy-logic in terms of EC, packet loss ratio and routing stability. It was found that the fuzzy-based approach-that was proposed- has outperformed ETX-RPL in terms of end-to-end delay and packet loss ratio. Furthermore, the proposed approach built a more stable topology in comparison to ETX-RPL with. Figure 6 below, depicts Fuzzy Inference Engine of proposed fuzzy-logic.

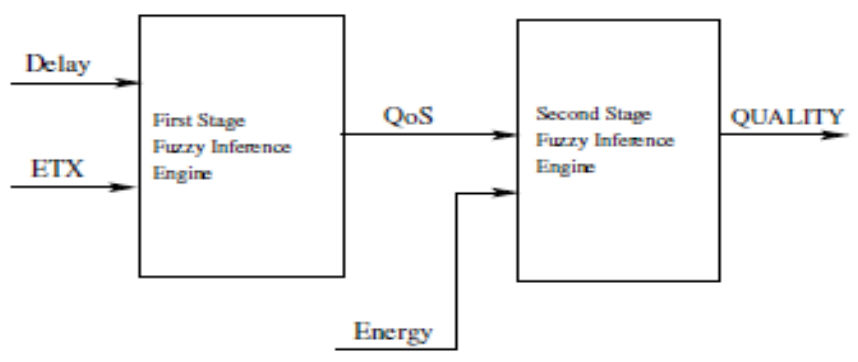

Figure 6. Fuzzy Inference Engine of proposed fuzzy-logic

(Musaddiq et al. 2018) proposed an efficient energy-aware adaptive trickle (EAAT) timer mechanism. This mechanism aims at adjusting the DIO transmission in accordance with the residual energy (RE) and future energy (FE). The FE is calculated based on Equation 11:

$$
\mathrm{FE}=\mathrm{ETX} . \mathrm{WL} \cdot \mathrm{e}(\mathrm{d})
$$

WL stands for the workload of the elected parent node. e(d) stands for the energy required for transmitting one packet at a distance $d$. The node ranks were set and establish in the DIO message along with their RE values. The change of trickle redundancy constant $\mathrm{k}$ can influence the number of the DIO messages transmission. Regarding the parent, it measures its current RE and value of FE. The $\mathrm{k}$ value was calculated as shown in Equation 12:

$$
K=[R E \%-F E \%]
$$

The proposed EAAT operates in sequential manner starts with the elected parent start to measure the number of the routing metrics for the current intervals. Primarily, a node shall measure the link quality based on the ETX. This metric shall predict the paths with lowest expected number of transmissions is needed which indicates the node EC in transmission phase. Then, a workload is measured that indicates the capacity of buffer. The node measures its RE by measuring the energy need through packets, processing, transmission, idle state energy, and reception. Every node obtains rank based on EAAT calculation. This rank information is attached to update child node and DIO message. Every node sets the trickle setting in accordance with the FE and RE values. The EAAT can manage the energy hotspot nodes through balancing the EC and control traffic overheads. The results obtained from simulation show that EAAT can increase the lifetime of the network and improves the performance of routing.

A study which optimized RPL OF to select best parent using the fuzzy logic was proposed by (Santiago \& Arockiam 2017). The proposed OF used a Three phase fuzzy logic procedure to integrate five linguistic input variables HC, energy, ETX , delay and Throughput: In the first phase, the ETX and delay are integrated to produce output variables call Quality of Service $(\mathrm{QoS})$. Through the second phase, the energy, hop count and Throughput are integrated to produce output variables call Route Quality (RQ).The third phase includes two inputs. These inputs are considered the output resulting from second and first phases. Output fuzzy of all phases is new Rank, which indicate the best parent. Figure 7 depicts Fuzzy Interface System. 


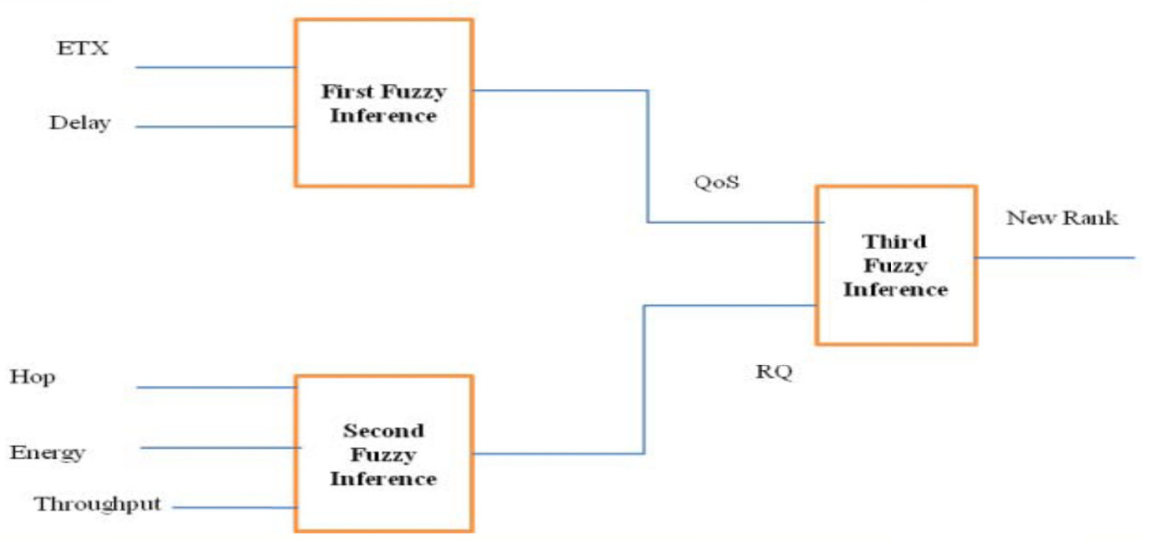

Figure 7. Fuzzy Interface System

The membership functions of first fuzzy output QoS are considered very low, slow, average, fast and very fast. The membership functions of second output RQ are awful, bad, degraded, average, acceptable, good and excellent.

\subsubsection{Remaining Energy}

The RE metric refers to the energy which resides or still in the nodes. Many researchers consider RE as the only metric and other combine with other metrics to calculate the path.

In (Kamgueu et al. 2013) an OF was proposed namely; OF-energy that use a RE as the only metric to select the next hop toward the sink. The proposed method uses a single metric same as standard routing protocol such as MRHOF \& OF0. That result indicates that the OF-energy provides more satisfactory results through the energy distribution between all nodes to ensure transition accuracy. As a result, the network lifetime will increase. However, this OF cannot be able to accommodate the link quality of network due to using an energy as metric.

Also, (Nurmio et al. 2015) proposed an OF based on nodes' RE to equally distribute energy among all nodes. The main goal was to extend network lifetime. The OF was designed based on ETX and parent node RE to find best preferred parent. Experiments were conducted on Contiki OS and its Cooja simulator. Results showed that proposed OF increases first node lifetime compared to MRHOF. It was also found that EC rate through network nodes using the proposed energy-aware OF was closer to each other compared to network nodes using MRHOF.

(Yunis \& Dujovne 2014) evaluated the performance of different metrics and proposed a mixture of HC and RE under multiple restrictions for reducing the power consumption dispersion on the network in order to increase LLN nodes lifetime. LLN nodes use the IEEE 802.15.4 standard and nodes allow point-to-point, multipoint-to-point and point-to-multipoint traffic patterns. Simulation conducted using J-Sim simulator and they used Average latency, Average packet loss, Average Power Consumption and Average number of dead nodes as evaluation matrices. Simulation results showed that a mixture of the HC and RE metrics shall decrease power consumption. That applies even in node loss conditions without incrementing latency or packet loss.

(Taghizadeh et al. 2018) tried to solve the dynamic load networks limitation in current RPL. A new routing protocol was introduced. This protocol is called Context-aware and Load-balancing RPL (CLRPL). It aims at minimizing the packet loss ratio and maximizing the network lifetime in LLN with highly-variable traffic and heavy throughput. The CLRPL protocol is consisting of three phases. The first phase, called CAOF (Context-aware OF), in this phase the OF calculates the rank of node using ETX, residual energy for the node and its parent, and the parent's rank. The latter information is added to DIO messages. It's stored by the node. That's done after receiving it. After measuring the rank of each DIO sender based on the saved information, CAOF employs an algorithm for sorting the nodes based on the rank (ranging from the best ones to the worst ones). Therefore, DIO that has the preferable rank is broadcasted first. As for the second phase, it's called the CARF (Context-Aware Routing Metric). CARF employs information that concerns the status of the queue chain in path. It employs information that concerns the rank of the node that was calculated through using the CAOF. It also employs information that concerns the index of the network traffic dynamicity for obtaining a value to be used in choosing parent. As in CAOF, the information employed by CARF is carried in the DIO. The Third phase is a parent selection mechanism. This mechanism aims at choosing the parents that has the lower value calculated by CARF. In case both of the candidate parents have the same value of CARF or not, the mechanism 
shall choose the parent that has the lower number of children nodes. The three phases are considered directly linked and exercise cooperative work. Therefore, through considering the workload of the paths together with information about link quality and energy, CLRPL is capable of reducing the consumption of energy and enhancing the packet loss rate. Thus, CLRPL shall reduce the changes of the best parent and EC where it increases packet loss ratio. Moreover, it increased end-to-end delay.

(Lazarevskal et al. 2018) proposed a novel OF for RPL called NEWOF to provide energy efficient and reliable parent selection for healthcare. The NEWOF was built based on additive metric approach consists from several metrics (i.e. reliability, mobility and EC). The NEWOF employed three metrics for calculating the best path namely: RE, ETX and RSSI.ETX illustrate the reliability through the overall number of link layer transmissions for producing a transmission successfully. The RE of the node illustrates the subtraction between the initial energy of the node and the consumed energy. As for the RSSI, it's a signal strength in a WSN illustrate the current power in a received radio signal, while link being assumed. The RSSI changes based on the location sensor nodes, thus representing the dynamics of the nodes. In the study select best parent is done by comparison of the path costs of the potential parents. The path cost is measured by adding the rank and the link cost, where the link cost used additive function of the chosen metrics (RE, ETX and RSSI) with different weight values for each metrics. Both rank and path cost measured based on the following Equations (13-16). The rank stands for a monotonously increasing function which is employed to avoid loops and chooses the non-optimal paths for routing.

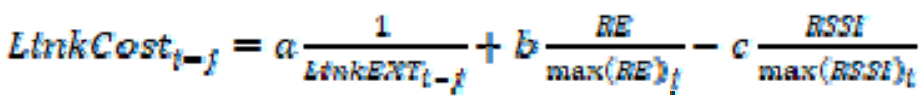

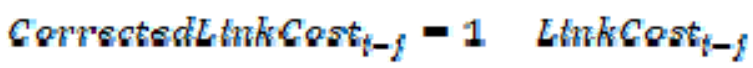

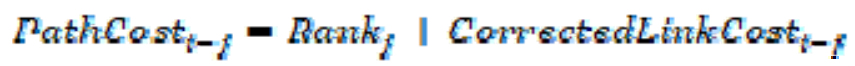

$$
\begin{aligned}
& \text { Romk }=I^{2} \text { athessti-l }
\end{aligned}
$$

(Mortazavi \& Khansari 2018) had proposed an RPL routing protocol for Internet of Multimedia Things through considering RE of nodes in the routing of IoT traffic. RE routing metric was calculated using Equation 17:

$$
R E=\frac{E t}{E R}
$$

Where Ei indicates the node's initial energy and ER indicates the node's RE. In case the node is idle and didn't consume energy, the ER value shall be equal to 1, and the ER amount shall increase with reducing the amount of the RE of each node. When the node die, the ER value is consider one. ER is calculated using the following Equation:

$$
F r^{r}=F i-F r
$$

EC stands for node Energy Consumption. It's calculated in accordance with the amount of the packets received and sent. The results of simulation indicate that employing the proposed RPL protocol shall enhance the network's lifetime while distributing the load of multimedia traffic routing between all routers. It shall extend the availability of nodes by $34 \%$ in comparison to the standard RPL protocol.

(Santiago et al. 2018) proposed on energy aware load balancing algorithm (EALBA) for IoT network through employing the event rate. The proposed algorithm adopts the Nested Un-weighted Pair Group Method (UPGM) with event rate. As for the algorithm process, it consists from two stages; Cluster UPGM and Expected Lifetime Time (ELT) for choosing parent. That's followed with forwarding packets. The EALBA algorithm proves the lifetime of the devices. It improves the lifetime of the parent nodes for network. The EALBA algorithm stores a significant amount of energy. However, the disadvantages of EALBA algorithm; it ignored investigating overhead, scalability and fault tolerance. EALBA algorithm was implemented through Cooja simulator and Contiki OS. The results showed that proposed technique Improved network lifetime and decreased EC.

(Mishra \& Chinara 2019) proposed a protocol Clustered Additive RPL it's named (CA-RPL). This protocol employs a weight-based clustering method for meeting the efficiency of a scalable network. The node calculates the rank through combining three parameters (i.e. ETX, HC, \& available energy). CA-RPL applies clustering in it, the cluster heads are chosen based on the battery power of a node. They are chosen based on the degree connectivity of a node. CA-RPL was simulated through using COOJA simulator in Contiki OS. It was noticed 
that the CA-RPL outperforms HC-RPL, ETX-RPL and Additive-RPL. It outperforms them in terms of end to end delay, PDR and EC in network.

(Sankar \& Srinivasan 2018b) proposed a fuzzy logic-based energy aware routing protocol called (FLEA-RPL). They consider three linguistic input variables (i.e., ETX, routing metrics load and residual energy (RER)). The output is considered the best route selection. FLEA-RPL applies fuzzy logic on those input metrics for choosing the best route to be transferred to the network data in an efficient manner. The membership function evaluates the linguistic input variable, to provide the accurate measurement of input and output variable. Authors select the trapezoidal shape membership function for input variable and triangle shape membership function for output variable in the fuzzy logic system. Based on the results of simulation, the FLEA-RPL enhances the lifetime of the network by $12 \%-10 \%$. It enhances the ratio of the packet delivery by $2 \%-5 \%$.Figure 8 shows FLEA-RPL system.

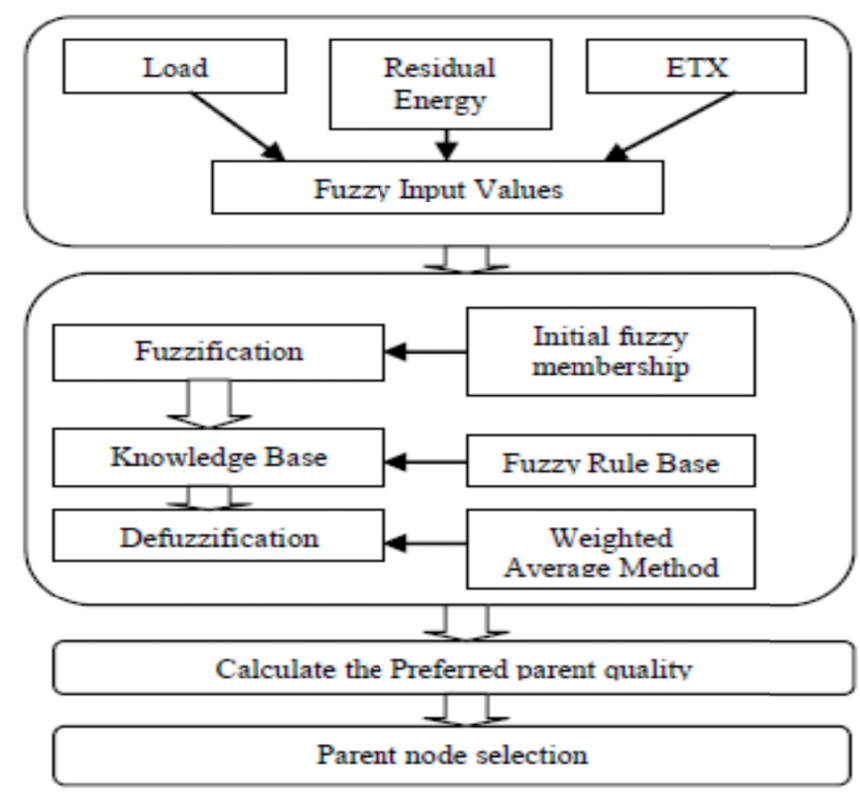

Figure 8. FLEA-RPL System

(Nassar et al. 2017) proposed an enhanced OF with a multi-objective metric that considers the RE and delay the in the battery nodes alongside with the quality of the links called OFQS. The proposed OFQS automatically adapts to the number of instances offering a QoS differentiation based on the different Smart Grid application-related requirements. OFQS is based on MRHOF as it relies on the same rank calculation method. OFQS adopts hysteresis for preventing the routing instabilities and decreasing the parent switches under a specific threshold. Based on the simulations results, OFQS offers a packet delivery latency that is low. It offers a PDR that is higher. It extends the lifetime of the network more than MRHOF and OF0.

\subsubsection{Battery Discharge}

Battery discharge Index (BDI) indicates how much percentage of energy depleted from battery present in the node. The index of battery discharge derives from residual energy. As for the residual energy, it calculates from each node of RER (Ni), i.e., current energy and initial one. The formula used for the residual energy calculation is provided in Equation (17).

$$
R E R(N i)=\frac{\text { Ecurrent }}{\text { Einitial }}
$$

Regarding the Battery discharge Index, it calculates for node "Ni" as (1- Residual Energy). The way of calculating BDI (Ni) is illustrated through Equation (18).

$$
B D I(N i)=(1-R E R(N i))
$$

(Sankar \& Srinivasan 2017) proposed a new RPL routing metrics for LLNs namely (LE-RPL). It uses a composite routing metric Load and battery discharge index (BDI). These composite metrics used to balance the data traffic to enhance the energy efficiency. The rank calculates from minimum load and BDI values of the node. The participant node chooses the parent deemed the best from DODAG. The simulation was conducted through employing COOJA network simulator. The performance of the proposed work was assessed in terms of the ratio 
of PDR and the lifetime of network. Based on the results of the experiment, the proposed system offers a better level of performance. It is associated with lower level of packet loss ratio. Also, it enhances the lifetime of the network more than the existing OF0, RER, ETX, Load and RER (BDI).

(Hassan et al. 2016) proposed a new composite metrics based RPL protocol in LLNs namely RERBDI. The EC of the battery powered sensing devices during the network operations can significantly affect the lifetime of the network in case there is a route selection that's inefficient, the energy depletion from even a few nodes in the network can cause damage to the network reliability and integrity. Such damage can occur through creating holes within the concerned network. RERBDI based on residual energy (RER), battery discharge index (BDI) and ETX for enhancing the energy conservation on the constituent nodes. Simulations were conducted for comparing its performance level with RER and ETX. It was found that the proposed scheme enhances the lifetime of the network through preferring routes with high average residual energy, and at the same time ensuring that energy depleted nodes aren't overburdened while carrying out the process of the route computation

(Sankar \& Srinivasan 2018a) proposed a new energy and load aware routing protocol (EL-RPL). EL-RPL is a composite routing metrics protocol. In fact, it's based on the combination of battery depletion index (BDI), load and ETX. Where other existing work does not consider the load metric in combination with ETX and BDI. In EL-RPL, the participant node chooses the parent deemed the best among the preferred parent based on DODAG rank. The rank is calculated from OF and rank increase. Each node and link associates with Load, BDI and ETX metrics in LLNs. EL-RPL is compared with other similar protocols RER (BDI) RPL and fuzzy logic based RPL (OF-FL RPL). Based on the results of simulation, EL-RPL offers better performance in terms of PDR, lifetime of the network, and end-to-end delay in comparison with OF-FL RPL and RERBDI RPL.

\subsection{Number of Connected Neighbors}

This metric denotes the connectivity between a node and its neighbor. Each node will be connected to its one-hop neighbors for performing data transmission.

(Aljarrah 2017) proposed a multi fuzzy logic model for OF for RPL (Ml-FL). This model consists of three metrics: channel-oriented, node-oriented and link-oriented ones for uncasing. The Ml-FL chooses the parent deemed the best for unicast through 9 individual metrics. Three other parameters were used for defining each one of the 9 metrics. That was done for ensuring that the parent node selection shall be effective. For overcoming fuzzy logic complexity, multiple fuzzy logic blocks were processed in parallel. In addition, an enhanced- BMRF algorithm was proposed with the minimum level of delay and duplicate packets. IEEE 802.15.4 standard was applied over OMNeT++ simulator for evaluating the effectiveness of the proposed RPL. The outcomes that were reached through employing the proposed RPL are considered promising in terms of end to end delay, energy, HC, packet delivery ratio and packet loss rate.

\subsection{Maximum Lifetime}

(Iova et al. 2014) designed a routing metric -that's new- for extending the lifetime of the network through balancing the load energy. This ELT metric made RPL provide closer performance to ETX in regard of delay and reliability. Furthermore, ELT had registered the best worst case among others in terms of the delay. In addition ELT showed an EC that's lower and an energy balanced topology that is higher.

\section{Summary of Node Metrics Related Research}

A comparison between of the most relevant research efforts regarding the RPL OFs are discussed in this section in term of metrics that used, metrics composition, description, objectives weakness, performance evaluation metrics and the method that used in evaluation as shown in table 1 . 
Table 1. Summary of Node Metrics related research

\begin{tabular}{|c|c|c|c|c|c|c|c|}
\hline Ref & Metrics & $\begin{array}{c}\text { Metric } \\
\text { composition }\end{array}$ & Description & Objectives & disadvantages & $\begin{array}{c}\text { Performance } \\
\text { evaluation } \\
\text { metrics }\end{array}$ & $\begin{array}{c}\text { Compared } \\
\text { with }\end{array}$ \\
\hline $\begin{array}{c}\text { (Aljarrah } \\
\text { 2017) }\end{array}$ & $\mathrm{RE}$ & $\begin{array}{l}\text { Single } \\
\text { metric }\end{array}$ & $\begin{array}{l}\text { design an OF for } \\
\text { RPL which } \\
\text { employed node RE } \\
\text { as a metric }\end{array}$ & $\begin{array}{l}\text { For increasing } \\
\text { the network } \\
\text { life time and } \\
\text { distributes } \\
\text { energy evenly } \\
\text { among nodes } \\
\text { without } \\
\text { having low } \\
\text { level of } \\
\text { transmission } \\
\text { accuracy }\end{array}$ & $\begin{array}{l}\text { 1. Using only } \\
\text { one metric } 2 \text {. } \\
\text { More packet } \\
\text { loss }\end{array}$ & $\begin{array}{c}\text { 1.Remaining } \\
\text { Power } \\
\text { Distribution } \\
2 . \\
\text { Transmission } \\
\text { Accuracy }\end{array}$ & MRHOF \\
\hline $\begin{array}{l}\text { (Kamgueu } \\
\text { et al. 2015) }\end{array}$ & $\begin{array}{l}\text { RE, ETX } \\
\text { and Delay }\end{array}$ & Fuzzy logic & $\begin{array}{l}\text { Design anew RPL } \\
\text { OF that involves } \\
\text { several metrics that } \\
\text { use fuzzy logic }\end{array}$ & $\begin{array}{c}\text { To } \\
\text { minimizing } \\
\text { end to end } \\
\text { delay, reduce } \\
\text { the rate of } \\
\text { packet loss } \\
\text { and minimize } \\
\text { the EC during } \\
\text { data } \\
\text { transmission. }\end{array}$ & $\begin{array}{l}\text { 1. Regarding } \\
\text { the slightly } \\
\text { improved } \\
\text { delay and the } \\
\text { enhanced } \\
\text { stability, they } \\
\text { aren't } \\
\text { justified. } \\
\text { 2. Very } \\
\text { low-quality } \\
\text { paths still } \\
\text { could be } \\
\text { chosen. } \\
\text { 3. of-fuzzy } \\
\text { compared only } \\
\text { with the ETX } \\
\text { that use a } \\
\text { single metrics. } \\
\text { 4. Does not } \\
\text { consider } \\
\text { mobility. }\end{array}$ & $\begin{array}{l}\text { 1. Packet Loss } \\
\text { Ratio } \\
\text { 2.Routing } \\
\text { Stability } \\
\text { 3.Average } \\
\text { Remaining } \\
\text { Power } \\
\text { 4.End-to-end } \\
\text { delay }\end{array}$ & MRHOF \\
\hline $\begin{array}{l}\text { (Nurmio et } \\
\text { al. 2015) }\end{array}$ & $\begin{array}{c}\mathrm{RE} \text { and } \\
\text { ETX }\end{array}$ & combination & $\begin{array}{c}\text { propose } 2 \text { OFs } \\
\text { (PEOF) and(PEOF2) } \\
\text { In the aim of } \\
\text { equalizing the } \\
\text { distribution of } \\
\text { energy among the } \\
\text { nodes with an } \\
\text { extension of the } \\
\text { lifetime of the } \\
\text { network }\end{array}$ & $\begin{array}{l}\text { To extended } \\
\text { network } \\
\text { lifetime and } \\
\text { equalized the } \\
\text { consumption } \\
\text { of energy. }\end{array}$ & $\begin{array}{l}\text { 1. Al most } \\
\text { Similar packet } \\
\text { delivery ratio } \\
\text { with MRHOF. } \\
\text { 2. Compared } \\
\text { to the standard } \\
\text { MRHOF only }\end{array}$ & $\begin{array}{c}\text { 1.RE } \\
\text { 2.Packet } \\
\text { delivery ratio }\end{array}$ & MRHOF \\
\hline $\begin{array}{c}\text { (Yunis \& } \\
\text { Dujovne } \\
2014 \text { ) }\end{array}$ & $\begin{array}{l}\text { RE, HC, } \\
\text { ETX and } \\
\text { PFI }\end{array}$ & $\begin{array}{c}\text { Combinatio } \\
\mathrm{n}\end{array}$ & $\begin{array}{c}\text { Design a new RPL } \\
\text { OF which involves } \\
\text { HC and RE }\end{array}$ & $\begin{array}{c}\text { To reduce } \\
\text { power } \\
\text { consumption } \\
\text { under node } \\
\text { loss } \\
\text { conditions } \\
\text { without }\end{array}$ & $\begin{array}{c}\text { 1.No } \\
\text { consideration } \\
\text { of link metrics } \\
\text { 2.With PFI: no } \\
\text { retransmission } \\
\text { is }\end{array}$ & $\begin{array}{c}\text { 1Average } \\
\text { latency } \\
\text { 2.Average } \\
\text { packet loss } \\
\text { 3.Average } \\
\text { Power }\end{array}$ & $\begin{array}{c}100 \% \mathrm{HC} \\
100 \% \mathrm{ETX} \\
100 \% \mathrm{PFI} \\
100 \% \mathrm{ENG} \\
75 \% \mathrm{HC}+ \\
25 \% \mathrm{PFI}\end{array}$ \\
\hline
\end{tabular}




\begin{tabular}{|c|c|c|c|c|c|c|c|}
\hline & & & & $\begin{array}{l}\text { raising the } \\
\text { latency nor } \\
\text { the packet } \\
\text { loss }\end{array}$ & a guarantee & $\begin{array}{l}\text { Consumption } \\
\text { 4.Average } \\
\text { number of } \\
\text { dead nodes }\end{array}$ & $\begin{array}{l}75 \% \mathrm{HC}+ \\
25 \% \text { ETX }\end{array}$ \\
\hline $\begin{array}{c}\text { (Aljarrah } \\
\text { 2017) }\end{array}$ & $\begin{array}{c}\text { RE, ETX, } \\
\text { neighbors } \\
\text { connectivit } \\
\text { y } \\
\text { capacity, } \\
\text { RSRQ, } \\
\text { bandwidth } \\
\text { link } \\
\text { stability, } \\
\text { HC and } \\
\text { mobility }\end{array}$ & $\begin{array}{l}\text { Multi-Fuzzy } \\
\text { model }\end{array}$ & $\begin{array}{c}\text { Propose OF based } \\
\text { on a Multi fuzzy } \\
\text { logic model. The } \\
\text { model considers } \\
3 \text { categories of } \\
\text { metrics (i.e. channel, } \\
\text { node, \& link } \\
\text { metrics) }\end{array}$ & $\begin{array}{l}\text { For the } \\
\text { improvement } \\
\text { of PDR, } \\
\text { delay, energy } \\
\& \text { HC }\end{array}$ & $\begin{array}{c}\text { Comparison } \\
\text { simulation } \\
\text { Environments } \\
\text { are not same } \\
\text { ML-FL is } \\
\text { tested in } \\
\text { OMNET++ } \\
\text { but OF-FL } \\
\text { and OF0 are } \\
\text { tested in } \\
\text { cooja }\end{array}$ & $\begin{array}{c}\text { 1. Average HC } \\
\text { 2. Packet loss } \\
\text { ratio } \\
\text { 3.Average } \\
\text { number of } \\
\text { parent changes } \\
\text { 4.Energy } \\
\text { utilization } \\
\text { 5. Delay } \\
\text { 6.Packet } \\
\text { Delivery Ratio }\end{array}$ & $\begin{array}{l}\text { OF-FL } \\
\text { OF0 }\end{array}$ \\
\hline $\begin{array}{l}\text { (Taghizadeh } \\
\text { et al. 2018) }\end{array}$ & $\begin{array}{l}\text { RE, queue } \\
\text { utilization, } \\
\text { and context } \\
\text { awareness }\end{array}$ & $\begin{array}{l}\text { Proposed } \\
\text { their own } \\
\text { combination } \\
\text { of OFs }\end{array}$ & $\begin{array}{l}\text { Propose a new RPL } \\
\text { version named } \\
\text { context-aware and } \\
\text { load balancing } \\
\text { protocol, CLRPL in } \\
\text { order to solve the } \\
\text { problem of handling } \\
\text { the heavy and } \\
\text { dynamic loads in the } \\
\text { standard RPL. }\end{array}$ & $\begin{array}{l}\text { 1. increases } \\
\text { the network } \\
\text { lifetime } \\
\text { 2. Decrease } \\
\text { the packet } \\
\text { loss and } \\
\text { overhead. }\end{array}$ & $\begin{array}{c}\text { 1. Not } \\
\text { considering } \\
\text { fault tolerance. } \\
\text { 2. Compared } \\
\text { only to the } \\
\text { standard RPL }\end{array}$ & $\begin{array}{l}\text { 1. queue loss } \\
\text { ratio } \\
\begin{array}{c}\text { 2. Packet loss } \\
\text { ratio }\end{array} \\
\text { 3. Number of } \\
\text { alive nodes. } \\
\text { 4. Network } \\
\text { lifetime. } \\
\text { 5. Network } \\
\text { energy } \\
\text { consummation } \\
\text {. } \\
\text { 6. DIO } \\
\text { overhead. } \\
\text { 7. Parent } \\
\text { change. } \\
\text { 8.inter packet } \\
\text { arrival }\end{array}$ & RPL \\
\hline $\begin{array}{l}\text { (Lazarevska } \\
1 \text { et al. 2018) }\end{array}$ & $\begin{array}{l}\text { RE ETX, } \\
\text { RSSI }\end{array}$ & $\begin{array}{l}\text { Additive } \\
\text { approach }\end{array}$ & $\begin{array}{l}\text { Design a theoretical } \\
\text { framework for RPL } \\
\text { aims at offering } \\
\text { energy efficiency } \\
\text { with taking into } \\
\text { consideration the } \\
\text { mobility of the } \\
\text { sensor nodes in } \\
\text { WSNs for mobile } \\
\text { and static nodes. }\end{array}$ & $\begin{array}{l}\text { For offering a } \\
\text { parent } \\
\text { selection } \\
\text { that's energy } \\
\text { efficient and } \\
\text { reliable in a } \\
\text { mobile } \\
\text { environment } \\
\text { for smart } \\
\text { healthcare }\end{array}$ & $\begin{array}{l}\text { Not good for } \\
\text { mobile node. }\end{array}$ & $\begin{array}{c}\text { 1. Average } \\
\text { Total Control } \\
\text { Traffic } \\
\text { Overhead } \\
\text { 2. Packet } \\
\text { Delivery Ratio } \\
\text { 3. Duty Cycle } \\
\text { 4. Average EC }\end{array}$ & MRHOF \\
\hline $\begin{array}{l}\text { (Lazarevska } \\
\text { 1 et al. 2018) }\end{array}$ & $\mathrm{RE}$ & $\begin{array}{l}\text { Additive } \\
\text { approach }\end{array}$ & $\begin{array}{c}\text { propose an RPL } \\
\text { routing protocol that } \\
\text { considers the RE of } \\
\text { nodes for } \\
\text { Multimedia Things }\end{array}$ & $\begin{array}{l}\text { To enhance } \\
\text { lifetime of the } \\
\text { network by } \\
\text { extends the } \\
\text { nodes' } \\
\text { availability. }\end{array}$ & $\begin{array}{l}\text { Total EC of } \\
\text { network nodes } \\
\text { almost same } \\
\text { with total } \\
\text { MORHF. } \\
\text { 2. Compared } \\
\text { only to }\end{array}$ & $\begin{array}{l}\text { 1. Average } \\
\text { Network } \\
\text { Lifetime } \\
\text { 2. Nodes } \\
\text { Availability } \\
\text { Index } \\
\text { 3. Distribution }\end{array}$ & MRHOF \\
\hline
\end{tabular}




\begin{tabular}{|c|c|c|c|c|c|c|c|}
\hline & & & & & MRHOF & $\begin{array}{c}\text { of nodes RE } \\
\text { 4. RE }\end{array}$ & \\
\hline $\begin{array}{l}\text { (Santiago et } \\
\text { al. 2018) }\end{array}$ & $\begin{array}{l}\text { ETX, HP } \\
\text { and ELT. }\end{array}$ & $\begin{array}{c}\text { Combinatio } \\
\mathrm{n}\end{array}$ & $\begin{array}{l}\text { propose a method } \\
\text { that adopts the } \\
\text { Nested Unweighted } \\
\text { Pair Group } \\
\text { Method with event } \\
\text { rate for handling the } \\
\text { energy-aware load } \\
\text { balancing issue. }\end{array}$ & $\begin{array}{l}\text { To Improve } \\
\text { network } \\
\text { Lifetime and } \\
\text { decrease EC }\end{array}$ & $\begin{array}{c}\text { 1.Ignored } \\
\text { investigating } \\
\text { scalability, } \\
\text { fault tolerance } \\
\text { and overhead } \\
\text { 2. Compared } \\
\text { to the } \\
\text { standard RPL } \\
\text { only }\end{array}$ & $\begin{array}{c}\text { 1.Maximum } \\
\text { Energy } \\
\text { 2. EC }\end{array}$ & RPL \\
\hline $\begin{array}{c}\text { (Mishra \& } \\
\text { Chinara } \\
\text { 2019) }\end{array}$ & $\begin{array}{c}\text { ETX ,HC } \\
\text { and } \\
\text { available } \\
\text { energy } \\
\text { (AE) }\end{array}$ & $\begin{array}{l}\text { Additive } \\
\text { approach }\end{array}$ & $\begin{array}{l}\text { Propose congestion } \\
\text { a multipath routing } \\
\text { protocol and } \\
\text { avoidance through } \\
\text { the use of a } \\
\text { composite routing } \\
\text { metric. }\end{array}$ & $\begin{array}{l}\text { For reducing } \\
\text { the ratio of } \\
\text { the packet } \\
\text { loss and the } \\
\text { time delay }\end{array}$ & $\begin{array}{l}\text { 1.not sufficient } \\
\text { to improve } \\
\text { RPL to avoid } \\
\text { congestion } \\
\text { 2. Compared } \\
\text { only to the } \\
\text { RPL }\end{array}$ & $\begin{array}{l}\text { 1.Ratio of } \\
\text { packet } \\
\text { delivery } \\
\text { 2.Average end } \\
\text { to end delay } \\
\text { 3. Average } \\
\text { radio on time } \\
\text { 4. Average } \\
\text { power } \\
\text { consumption } \\
\text { 5. Average } \\
\text { duty cycle }\end{array}$ & $\begin{array}{c}\text { Additive-RP } \\
\text { L } \\
\text { MRHOF } \\
\text { HC-RPL }\end{array}$ \\
\hline $\begin{array}{c}\text { (Sankar \& } \\
\text { Srinivasan } \\
\text { 2018b) }\end{array}$ & $\begin{array}{l}\text { ETX , load } \\
\text { traffic } \\
\text { Residual } \\
\text { energy } \\
\text { (RER) }\end{array}$ & Fuzzy logic & $\begin{array}{c}\text { Proposing a fuzzy } \\
\text { logic that is based on } \\
\text { energy aware routing } \\
\text { protocol }\end{array}$ & $\begin{array}{c}\text { For improving } \\
\text { the network } \\
\text { lifetime, PDR } \\
\text { and the } \\
\text { reduction of } \\
\text { end-to-end } \\
\text { delay }\end{array}$ & $\begin{array}{l}\text { The efficiency } \\
\text { of the } \\
\text { FLEA-RPL } \\
\text { isn't displayed } \\
\text { in terms of } \\
\text { overhead } \\
\text { and load } \\
\text { balancing }\end{array}$ & $\begin{array}{l}\text { 1. Average } \\
\text { Number of } \\
\text { Parent } \\
\text { Changes } \\
\text { 2. Average } \\
\text { End-to-End } \\
\text { Delay } \\
\text { 3. Average } \\
\text { Packet Loss } \\
\text { Ratio } \\
\text { 4. Average RE }\end{array}$ & $\begin{array}{c}\text { RPL } \\
\text { MRHOF } \\
\text { FL-RPL }\end{array}$ \\
\hline $\begin{array}{l}\text { (Nassar et } \\
\text { al. 2017) }\end{array}$ & $\begin{array}{c}\text { ETX, Delay } \\
\text { and } \\
\text { RE }\end{array}$ & $\begin{array}{c}\text { lexical } \\
\text { and } \\
\text { additive. }\end{array}$ & $\begin{array}{l}\text { Proposing an OF } \\
\text { that is new and } \\
\text { employs a } \\
\text { multi-objective } \\
\text { metric for } \\
\text { optimizing the RPL } \\
\text { protocol with the } \\
\text { smart grid } \\
\text { requirements in } \\
\text { terms of service } \\
\text { quality }\end{array}$ & $\begin{array}{l}\text { Improving the } \\
\text { lifetime of } \\
\text { network, } \\
\text { PDR, and End } \\
\text { to-End delay. }\end{array}$ & $\begin{array}{l}\text { Compared } \\
\text { with the } \\
\text { MRHOF and } \\
\text { OF0 only }\end{array}$ & $\begin{array}{c}\text { 1. Network } \\
\text { lifetime and } \\
\text { load balancing } \\
\text { 2. End-to-End } \\
\text { delay } \\
\text { 3. Packet } \\
\text { delivery ratio }\end{array}$ & $\begin{array}{c}\text { MRHOF } \\
\text { OF0 }\end{array}$ \\
\hline $\begin{array}{l}\text { (Shakya et } \\
\text { al. 2017) }\end{array}$ & $\begin{array}{c}\text { EC } \\
\text { and ETX }\end{array}$ & $\begin{array}{c}\text { Additive } \\
\text { combination }\end{array}$ & $\begin{array}{l}\text { Propose A new } \\
\text { parent selection } \\
\text { algorithm named } \\
\text { SEEOF } \\
\text { Developing a new } \\
\text { cost function to } \\
\text { carry out parent }\end{array}$ & $\begin{array}{l}\text { Utilizing the } \\
\text { EC in an } \\
\text { efficient } \\
\text { manner and } \\
\text { improving } \\
\text { improve } \\
\text { lifetime of }\end{array}$ & $\begin{array}{l}\text { 1.The } \\
\text { improvement } \\
\text { of the life time } \\
\text { of the network } \\
\text { hasn't been } \\
\text { significant } \\
2 \text {.No practical }\end{array}$ & $\begin{array}{c}\text { Packet } \\
\text { Delivery Ratio } \\
\text { (PDR) and } \\
\text { energy } \\
\text { consumption }\end{array}$ & MRHOF \\
\hline
\end{tabular}




\begin{tabular}{|c|c|c|c|c|c|c|c|}
\hline & & & $\begin{array}{l}\text { selection that takes } \\
\text { into consideration } \\
\text { both the link quality } \\
\text { and the energy in } \\
\text { terms of lifetime. }\end{array}$ & network & $\begin{array}{l}\text { testing. } \\
\text { 3. No } \\
\text { considerations } \\
\text { for mobility. } \\
\text { 4.Compared } \\
\text { only to } \\
\text { MRHOF }\end{array}$ & & \\
\hline $\begin{array}{c}\text { (Lamaazi \& } \\
\text { Benamar } \\
\text { 2018) }\end{array}$ & $\begin{array}{l}\text { ETX, HC } \\
\text { and EC }\end{array}$ & Fuzzy logic & $\begin{array}{l}\text { Proposing a new OF } \\
\text { based on combined } \\
\text { metrics through } \\
\text { using Fuzzy Logic } \\
\text { named (OF-EC) } \\
\text { considers the link } \\
\text { and the node } \\
\text { metrics. }\end{array}$ & $\begin{array}{l}\text { Improving } \\
\text { routing } \\
\text { performances } \\
\text { in terms of } \\
\text { overhead and } \\
\text { PDR and } \\
\text { allowing the } \\
\text { equalization } \\
\text { of the EC of } \\
\text { nodes } \\
\text { throughout } \\
\text { the network }\end{array}$ & $\begin{array}{l}\text { 1.Provide high } \\
\text { preferred } \\
\text { parent change. } \\
2 . \text { No } \\
\text { considerations } \\
\text { for mobility. }\end{array}$ & $\begin{array}{l}\text { PDR, network } \\
\text { lifetime, } \\
\text { overhead, } \\
\text { convergence } \\
\text { time, latency } \\
\text { and EC. }\end{array}$ & $\begin{array}{c}\text { OF-ETX, } \\
\text { ENTOT, } \\
\text { OF-FUZZY. }\end{array}$ \\
\hline $\begin{array}{c}\text { (Sousa et al. } \\
\text { 2017) }\end{array}$ & $\begin{array}{c}\text { EC and } \\
\text { ETX. }\end{array}$ & $\begin{array}{c}\text { Combinatio } \\
\mathrm{n}\end{array}$ & $\begin{array}{c}\text { Propose an Energy } \\
\text { Efficient and Path } \\
\text { Reliability Aware } \\
\text { OF (ERAOF) for } \\
\text { IoT } \\
\text { applications .ERAO } \\
\text { F is based on the } \\
\text { composition of } \\
\text { energy and link } \\
\text { quality routing } \\
\text { metrics. }\end{array}$ & $\begin{array}{l}\text { Improve } \\
\text { routing } \\
\text { performances, } \\
\text { offer high } \\
\text { packet } \\
\text { delivery ratio } \\
\text { for IoT } \\
\text { applications } \\
\text { with an } \\
\text { efficient } \\
\text { power } \\
\text { consumption } \\
\text { of network } \\
\text { resources. }\end{array}$ & $\begin{array}{l}\text { 1. Compared } \\
\text { only with } \\
\text { OF0, MRHOF. }\end{array}$ & $\begin{array}{c}\text { Packet } \\
\text { delivery ratio, } \\
\text { number of } \\
\text { hops, and } \\
\text { spent energy } \\
\text { for delivered } \\
\text { data packet. }\end{array}$ & $\begin{array}{c}\text { OF0 } \\
\text { MRHOF }\end{array}$ \\
\hline $\begin{array}{c}\text { (Lamaazi \& } \\
\text { Benamar } \\
\text { 2019) }\end{array}$ & $\begin{array}{c}\text { ETX and } \\
\text { EC. }\end{array}$ & Fuzzy logic & $\begin{array}{l}\text { Assessing the RPL } \\
\text { performances } \\
\text { based on its main } \\
\text { components (i.e. the } \\
\text { trickle algorithm \& } \\
\text { the OF) }\end{array}$ & $\begin{array}{c}2 \\
\text { enhancements } \\
\text { RPL-EC, } \\
\text { which is a } \\
\text { new OF that's } \\
\text { based on } \\
\text { combined } \\
\text { Metrics } \\
\text { through using } \\
\text { fuzzy logic, } \\
\text { and RPL-FL, } \\
\text { that is a } \\
\text { flexible } \\
\text { trickle } \\
\text { algorithm. } \\
\text { This } \\
\text { algorithm } \\
\text { resolves the } \\
\text { problems of }\end{array}$ & $\begin{array}{c}\text { 1.Only } \\
\text { compare with } \\
\text { slandered RPL }\end{array}$ & $\begin{array}{c}\text { overhead, } \\
\text { convergence } \\
\text { time, energy } \\
\text { consumption, } \\
\text { PDR and } \\
\text { network } \\
\text { lifetime. }\end{array}$ & RPL \\
\hline
\end{tabular}




\begin{tabular}{|c|c|c|c|c|c|c|c|}
\hline & & & & $\begin{array}{c}\text { the listen-only } \\
\text { period. }\end{array}$ & & & \\
\hline $\begin{array}{l}\text { (Musaddiq } \\
\text { et al. 2018) }\end{array}$ & $\begin{array}{c}\text { Future } \\
\text { energy (FE) } \\
\text { and RE. }\end{array}$ & $\begin{array}{c}\text { Combinatio } \\
\mathrm{n}\end{array}$ & $\begin{array}{l}\text { Propose an efficient } \\
\text { energy-aware } \\
\text { adaptive trickle } \\
\text { (EAAT) timer } \\
\text { mechanism for } \\
\text { scaling the DIO } \\
\text { transmission based } \\
\text { on the future energy } \\
(F E) \text { and the residual } \\
\text { energy }(R E) \\
\text { information. }\end{array}$ & $\begin{array}{l}\text { Enhancing } \\
\text { network } \\
\text { lifetime and } \\
\text { routing } \\
\text { performance. }\end{array}$ & $\begin{array}{l}\text { 1.evalute } \\
\text { using one } \\
\text { performanc } \\
\text { e metrics } \\
\text { 2.Compared } \\
\text { only with } \\
\text { RPL-ETX }\end{array}$ & $\begin{array}{l}\text { network } \\
\text { lifetime }\end{array}$ & MRHOF \\
\hline $\begin{array}{c}\text { (Santiago \& } \\
\text { Arockiam } \\
\text { 2017) }\end{array}$ & $\begin{array}{l}\text { Throughput } \\
\text {, Delay, HC } \\
\text { EC and } \\
\text { ETX }\end{array}$ & Fuzzy logic & $\begin{array}{l}\text { The proposed } \\
\text { system employs } \\
\text { fuzzy logic for } \\
\text { optimizing routing } \\
\text { Protocol based on } \\
\text { several routing } \\
\text { metrics. The system } \\
\text { use multi level of } \\
\text { fuzzy to find the best } \\
\text { path.. }\end{array}$ & $\begin{array}{l}\text { Enhance the } \\
\text { network } \\
\text { performance }\end{array}$ & $\begin{array}{l}\text { 1.Add more } \\
\text { complexity } \\
\text { 2.Compared } \\
\text { only with } \\
\text { RPL-ETX } \\
\text { 3.The } \\
\text { simulation } \\
\text { results are not } \\
\text { clear }\end{array}$ & $\begin{array}{c}\text { Route } \\
\text { Reliability } \\
\text { Energy } \\
\text { efficient }\end{array}$ & MRHOF \\
\hline $\begin{array}{c}\text { (Sankar \& } \\
\text { Srinivasan } \\
\text { 2017) }\end{array}$ & $\begin{array}{l}\text { Load and } \\
\text { (BDI) }\end{array}$ & $\begin{array}{c}\text { Additive } \\
\text { calculation }\end{array}$ & $\begin{array}{l}\text { Proposed a new RPL } \\
\text { routing metrics } \\
\text { namely (LE-RPL). It } \\
\text { uses a composite } \\
\text { routing metric Load } \\
\text { and (BDI) }\end{array}$ & $\begin{array}{l}\text { Balance the } \\
\text { data traffic in } \\
\text { order to } \\
\text { enhance the } \\
\text { energy } \\
\text { efficiency. }\end{array}$ & $\begin{array}{l}\text { 1. Does not } \\
\text { consider } \\
\text { mobility. }\end{array}$ & $\begin{array}{l}\text { 1. Packet } \\
\text { delivery } \\
\text { ratio } \\
\text { (PDR) } \\
\text { 2. network } \\
\text { lifetime }\end{array}$ & $\begin{array}{c}\text { OF0, } \\
\text { MRHOF } \\
\text {, RER, RER } \\
\text { (BDI) and } \\
\text { Load }\end{array}$ \\
\hline $\begin{array}{l}\text { (Hassan et } \\
\text { al. 2016) }\end{array}$ & $\begin{array}{l}\text { residual } \\
\text { energy } \\
\text { (RER), BDI } \\
\text { and ETX }\end{array}$ & $\begin{array}{l}\text { Composite } \\
\text { calculation }\end{array}$ & $\begin{array}{l}\text { a new composite } \\
\text { metrics based RPL } \\
\text { protocol in LLN } \\
\text { namely } \text { RER }_{\mathrm{BDI}}\end{array}$ & $\begin{array}{l}\text { Improving } \\
\text { energy } \\
\text { conservation } \\
\text { on the } \\
\text { constituent } \\
\text { nodes. }\end{array}$ & $\begin{array}{c}\text { 1.In the case } \\
\text { of inefficient } \\
\text { route } \\
\text { selection, the } \\
\text { energy } \\
\text { depletion can } \\
\text { damage } \\
\text { network } \\
\text { integrity and } \\
\text { reliability . } \\
\text { 2. Does not } \\
\text { consider } \\
\text { mobility. } \\
\text { 3.compared } \\
\text { with methods } \\
\text { that use only } \\
\text { one metric }\end{array}$ & $\begin{array}{l}\text { 1. Average } \\
\text { residual } \\
\text { energy. } \\
\text { 2. ensuring } \\
\text { that energy } \\
\text { depleted } \\
\text { nodes are } \\
\text { not } \\
\text { overburde } \\
\text { ned during } \\
\text { the route } \\
\text { computatio } \\
\text { n process }\end{array}$ & $\begin{array}{l}\text { MRHOF } \\
\text { and RER }\end{array}$ \\
\hline $\begin{array}{c}\text { (Sankar \& } \\
\text { Srinivasan } \\
\text { 2018a) }\end{array}$ & $\begin{array}{l}\text { load, BDI } \\
\text { and ETX }\end{array}$ & Additive & $\begin{array}{c}\text { proposed a new } \\
\text { energy and load } \\
\text { aware routing } \\
\text { protocol (EL-RPL) }\end{array}$ & $\begin{array}{l}\text { to get the best } \\
\text { parent node in } \\
\text { a network. }\end{array}$ & $\begin{array}{l}\text { 1.Does not } \\
\text { consider } \\
\text { mobility. }\end{array}$ & $\begin{array}{l}\text { 1. network } \\
\text { lifetime. } \\
\text { 2. packet } \\
\text { delivery }\end{array}$ & $\begin{array}{c}\text { RERBDI } \\
\text { RPL and } \\
\text { OF-FL RPL }\end{array}$ \\
\hline
\end{tabular}




\begin{tabular}{|c|c|c|c|c|c|c|c|}
\hline & & & & & & $\begin{array}{l}\text { 3. End-to-en } \\
\mathrm{d} \text { delay }\end{array}$ & \\
\hline $\begin{array}{c}\text { (Iova et al. } \\
\text { 2014) }\end{array}$ & $\begin{array}{l}\text { Expected } \\
\text { Lifetime }\end{array}$ & $\begin{array}{l}\text { Single } \\
\text { metric }\end{array}$ & $\begin{array}{l}\text { Designed a new } \\
\text { routing metric } \\
\text { namely ELT that } \\
\text { take into account its } \\
\text { residual energy, the } \\
\text { link reliability to its } \\
\text { neighbors and the } \\
\text { quantity of traffic to } \\
\text { forward. }\end{array}$ & $\begin{array}{c}\text { to extend } \\
\text { network } \\
\text { lifetime via } \\
\text { balancing } \\
\text { load energy }\end{array}$ & $\begin{array}{c}\text { 1.Single } \\
\text { metric OF } \\
\text { 2. ELT provide } \\
\text { worst delay } \\
\text { compared with } \\
\text { others }\end{array}$ & $\begin{array}{l}\text { Reliability } \\
\text { End-to-end } \\
\text { delay } \\
\text { EC }\end{array}$ & $\begin{array}{c}\text { ETX } \\
\text { Residual } \\
\text { energy }\end{array}$ \\
\hline
\end{tabular}

\section{Conclusion}

RPL is being one of the most attractive topics in networks field. Researchers had studied it thoroughly in the literature. One of the vital components of RPL is OF and it has been under study for the last decade. Due to massive amount of studies presented in this regard, a complete survey is needed to classify the work in order to simplify its study.

This Survey aimed at listing, discussing and explaining node metrics RPL research papers which studies different OF along with different metrics. OFs can be classified into single or multiple metrics one. The main conclusion of this survey is that compound metrics OF RPL outperformed single metric OF RPL.

\section{References}

Abdel-jaber, H., Mahafzah, M., Thabtah, F. \& Woodward, M. (2008, June). Fuzzy logic controller of Random Early Detection based on average queue length and packet loss rate. In 2008 International Symposium on Performance Evaluation of Computer and Telecommunication Systems (428-432). IEEE.

Abdel Hakeem, S. A., Hady, A. A. \& Kim, H. (2019). RPL Routing Protocol Performance in Smart Grid Applications Based Wireless Sensors: Experimental and Simulated Analysis. Electronics, 8(2), 186. https://doi.org/10.3390/electronics8020186

Saaidah, A, Almomani, O, Al-Qaisi,L. \& MADI,M.(2019).“An Efficient Design of RPL Objective Function for Routing in Internet of Things using Fuzzy Logic" International Journal of Advanced Computer Science and Applications (IJACSA). https://doi.org/10.14569/IJACSA.2019.0100824

Aissa, Y. B., Grichi, H., Khalgui, M., Koubâa, A. \& Bachir, A. (2019). QCOF: New RPL Extension for QoS and Congestion-Aware in Low Power and Lossy Network. https://doi.org/10.5220/0007978805600569

Aljarrah, E. (2017). Deployment of multi-fuzzy model based routing in RPL to support efficient IoT. International Journal of Communication Networks and Information Security, 9(3), 457-465.

Information Resources Management Association. (2015). Mobile Computing and Wireless Networks: Concepts, Methodologies, Tools, and Applications. IGI Global.

Al Balas, F., Almomani, O., Jazoh, R. M. A., Khamayseh, Y. M. \& Saaidah, A. (2019, April). An Enhanced End to End Route Discovery in AODV using Multi-Objectives Genetic Algorithm. In 2019 IEEE Jordan International Joint Conference on Electrical Engineering and Information Technology (JEEIT) (209-214). IEEE. https://doi.org/10.1109/JEEIT.2019.8717489

Barthel, D., Pister, K., Dejean, N., Vasseur, J. P. \& Kim, M. (2012). Routing metrics used for path calculation in low-power and lossy networks.

Bisen, A. \& Matthew, J. (2018, December). Performance Evaluation of RPL Routing Protocol for Low Power Lossy Networks for IoT Environment. In 2018 International Conference on Circuits and Systems in Digital Enterprise Technology (ICCSDET) (1-8). IEEE. https://doi.org/10.1109/ICCSDET.2018.8821163

Charles, A. J. \& Palanisamy, K. (2018, September). Attunement of Trickle Algorithm for Optimum Reliability of RPL over IoT. In International Symposium on Security in Computing and Communication (628-639). Springer, Singapore.

Culler, D., Estrin, D. \& Srivastava, M. (2004). Guest editors' introduction: Overview of sensor networks. Computer, 37(8), 41-49. https://doi.org/10.1109/MC.2004.93.

Dong, L. \& Li, R., 2019. RPL based Named Data Routing Protocol for Low Power and Lossy Wide Area Networks. In 2019 IEEE 5th World Forum on Internet of Things (WF-IoT). (442-447). 
https://doi.org/10.1109/WF-IoT.2019.8767345.

Gaddour, O., Koubâa, A., Baccour, N. \& Abid, M. (2014, May). OF-FL: QoS-aware fuzzy logic objective function for the RPL routing protocol. In 2014 12th International Symposium on Modeling and Optimization in Mobile, Ad Hoc, and Wireless Networks (WiOpt) (365-372). IEEE. https://doi.org/10.1109/WIOPT.2014.6850321.

Gaddour, O. \& Koubâa, A. (2012). RPL in a nutshell: A survey. Computer Networks, 56(14), 3163-3178. https://doi.org/10.1016/j.comnet.2012.06.016.

Gottwald, S. (2013). Fuzzy sets and fuzzy logic: The foundations of application-from a mathematical point of view. Springer-Verlag.

Hassan, A., Alshomrani, S., Altalhi, A. \& Ahsan, S. (2016). Improved routing metrics for energy constrained interconnected devices in low-power and lossy networks. Journal of communications and networks, 18(3), 327-332. https://doi.org/10.1109/JCN.2016.000048.

Ingoley, S. N. \& Nashipudi, M. (2012). A review: fuzzy logic in congestion control of computer network. In International Conference in Recent Trends in Information Technology and Computer Science (ICRTITCS).

Iova, O., Theoleyre, F. \& Noel, T. (2014, May). Improving the network lifetime with energy-balancing routing: Application to RPL. In 2014 7th IFIP Wireless and Mobile Networking Conference (WMNC) (1-8). IEEE. https://doi.org/10.1109/WMNC.2014.6878864.

Ji, C., Koutsiamanis, R. A., Montavont, N., Chatzimisios, P., Dujovne, D. \& Papadopoulos, G. Z. (2018, October). TAOF: Traffic Aware Objective Function for RPL-based Networks. In 2018 Global Information Infrastructure and Networking Symposium (GIIS) (1-5). IEEE. https://doi.org/10.1109/GIIS.2018.8635699.

Johnson, D. B., Maltz, D. A. \& Broch, J. (2001). DSR: The dynamic source routing protocol for multi-hop wireless ad hoc networks. Ad hoc networking, 5(1), 139-172.

Kamgueu, P. O., Nataf, E. \&Djotio, T. N. (2015, October). On design and deployment of fuzzy-based metric for routing in low-power and lossy networks. In 2015 IEEE 40th Local Computer Networks Conference Workshops (LCN Workshops) (789-795). IEEE. https://doi.org/10.1109/LCNW.2015.7365929.

Kamgueu, P. O., Nataf, E., Ndié, T. D. \& Festor, O. (2013). Energy-based routing metric for RPL.

Kamgueu, P. O., Nataf, E. \& Ndie, T. D. (2018). Survey on RPL enhancements: A focus on topology, security and mobility. Computer Communications, (10-21). https://doi.org/10.1016/j.comcom.2018.02.011.

Karkazis, P., Leligou, H. C., Sarakis, L., Zahariadis, T., Trakadas, P., Velivassaki, T. H. \& Capsalis, C. (2012, July). Design of primary and composite routing metrics for RPL-compliant wireless sensor networks. In 2012 International Conference on Telecommunications and Multimedia (TEMU) (13-18). IEEE. https://doi.org/10.1109/TEMU.2012.6294705

Kharrufa, H., Al-Kashoash, H. A. \& Kemp, A. H. (2019). RPL-based routing protocols in IoT applications: A Review. IEEE Sensors Journal, 19(15), 5952-5967. https://doi.org/10.1109/JSEN.2019.2910881.

Kim, H. S., Ko, J., Culler, D. E. \& Paek, J. (2017). Challenging the IPv6 routing protocol for low-power and lossy networks (RPL): A survey. IEEE Communications Surveys \& Tutorials, 19(4), 2502-2525. https://doi.org/10.1109/COMST.2017.2751617

Lamaazi, H. \& Benamar, N. (2019). A Novel Approach for RPL Assessment Based on the Objective Function and Trickle Optimizations. Wireless Communications and Mobile Computing. https://doi.org/10.1155/2019/4605095.

Lamaazi, H. \& Benamar, N. (2018). OF-EC: A novel energy consumption aware objective function for RPL based on fuzzy logic. Journal of Network and Computer Applications, 117, 42-58. https://doi.org/10.1016/j.jnca.2018.05.015.

Lamaazi, H., Benamar, N. \& Jara, A. J. (2018). RPL-based networks in static and mobile environment: A performance assessment analysis. Journal of King Saud University-Computer and Information Sciences, 30(3), 320-333. https://doi.org/10.1016/j.jksuci.2017.04.001.

Lamaazi, H., Benamar, N. \& Jara, A. J. (2016, May). Study of the Impact of Designed Objective Function on the RPL-Based Routing Protocol. In International Symposium on Ubiquitous Networking (67-80). Springer, Singapore. https://doi.org/10.1007/978-981-10-1627-1_6

Lazarevskal, M., Farahbakhsh, R., ManShakya, N. \& Crespi, N. (2018, October). Mobility Supported Energy 
Efficient Routing Protocol for IoT Based Healthcare Applications. In 2018 IEEE Conference on Standards for Communications and Networking (CSCN) (1-5). IEEE. https://doi.org/10.1109/CSCN.2018.8581828.

Mamdani, E. H. \& Assilian, S. (1975). An experiment in linguistic synthesis with a fuzzy logic controller. International journal of man-machine studies, 7(1), 1-13. https://doi.org/10.1016/S0020-7373(75)80002-2

Negnevitsky, M. (2005). Artificial intelligence: a guide to intelligent systems. Pearson education.

Mishra, S. N. \& Chinara, S. (2019, February). CA-RPL: A Clustered Additive Approach in RPL for IoT Based Scalable Networks. In International Conference on Ubiquitous Communications and Network Computing (103-114). Springer, Cham. http://dx.doi.org/10.1007/978-3-030-20615-4_8.

Mortazavi, F. \& Khansari, M. (2018, September). An Energy-Aware RPL Routing Protocol for Internet of Multimedia Things. In Proceedings of the international conference on smart cities and internet of things, (11).ACM. https://doi.org/10.1145/3269961.3269965.

Musaddiq, A., Zikria, Y. B. \& Kim, S. W. (2018, November). Energy-Aware Adaptive Trickle Timer Algorithm for RPL-based Routing in the Internet of Things. In 2018 28th International Telecommunication Networks and Applications Conference (ITNAC) (1-6). IEEE. https://doi.org/10.1109/atnac.2018.8615408.

Nassar, J., Gouvy, N. \& Mitton, N. (2017, November). Towards Multi-instances QoS Efficient RPL for Smart Grids. In Proceedings of the 14th ACM Symposium on Performance Evaluation of Wireless Ad Hoc, Sensor \& Ubiquitous Networks (85-92).ACM. https://doi.org/10.1145/3134829.3134838

Negnevitsky, M. (2005). Artificial intelligence: a guide to intelligent systems. Pearson education.

Nurmio, J., Nigussie, E. \& Poellabauer, C. (2015, October). Equalizing energy distribution in sensor nodes through optimization of RPL. In 2015 IEEE International Conference on Computer and Information Technology; Ubiquitous Computing and Communications; Dependable, Autonomic and Secure Computing; Pervasive Intelligence and Computing (83-91). https://doi.org/10.1109/CIT/IUCC/DASC/PICOM.2015.1.

Patel, D. R. (2008). Information security: theory and practice. PHI Learning Pvt.Ltd..

Rehman, A., Khan, M. M., Lodhi, M. A. \& Hussain, F. B. (2016, March). Rank attack using objective function in RPL for low power and lossy networks. In 2016 International Conference on Industrial Informatics and Computer Systems (CIICS) (1-5). IEEE. https://doi.org/10.1109/ICCSII.2016.7462418.

Rossides, L., Sekercioglu, A., Pitsillides, A., Vasilakos, A., Kohler, S. \& Tran-Gia, P. (2002). Fuzzy RED: Congestion control for TCP/IP diff-serv. In Advances in Computational Intelligence and Learning (343-352). Springer, Dordrecht. https://doi.org/10.1007/978-94-010-0324-7_24.

Sankar, S. \& Srinivasan, P. (2017). Composite metric based energy efficient routing protocol for internet of things. International Journal of Intelligent Engineering and Systems, 10(5), 278-286. https://doi.org/10.22266/ijies2017.1031.30

Sankar, S. \& Srinivasan, P., (2018a). Energy and Load Aware Routing Protocol for Internet of Things. International Journal of ADVANCED AND APPLIED SCIENCES, 7(3), 255-264. https://doi.org/10.11591/ijaas.v7.i3.pp255-264

Sankar, S. \& Srinivasan, P. (2018b). Fuzzy Logic Based Energy Aware Routing Protocol for Internet of Things. International Journal of Intelligent Systems and Applications, 10(10), 11. https://doi.org/10.5815/ijisa.2018.10.02

Santiago, S. \& Arockiam, L. (2017, February). A novel fuzzy based energy efficient routing for Internet of Things. In 2017 International Conference on Algorithms, Methodology, Models and Applications in Emerging Technologies (ICAMMAET) (1-4). IEEE. https://doi.org/10.1109/ICAMMAET.2017.8186645

Santiago, S., Kumar, A. \& Arockiam, L. (2018, May). EALBA: energy aware load balancing algorithm for IoT networks. In Proceedings of the 2018 International Conference on Mechatronic Systems and Robots (46-50).ACM. do:10.1145/3230876.3230880

Shakya, N. M., Mani, M. \& Crespi, N. (2017, June). SEEOF: Smart energy efficient objective function: Adapting RPL objective function to enable an IPv6 meshed topology solution for battery operated smart meters. In 2017 Global Internet of Things Summit (GIoTS) (1-6). IEEE. https://doi.org/10.1109/GIOTS.2017.8016252

Sharma, A. \& Kumar, R. (2016, December). Performance comparison and detailed study of AODV, DSDV, DSR, TORA and OLSR routing protocols in ad hoc networks. In 2016 Fourth International Conference on 
Parallel, Distributed and Grid Computing (PDGC) (732-736). IEEE. https://doi.org/10.1109/PDGC.2016.7913218

Sousa, N., Sobral, J. V., Rodrigues, J. J., Rabêlo, R. A. \& Solic, P. (2017, July). ERAOF: A new RPL protocol objective function for Internet of Things applications. In 2017 2nd International Multidisciplinary Conference on Computer and Energy Science (SpliTech) (1-5). IEEE.

Taghizadeh, S., Bobarshad, H. \& Elbiaze, H. (2018). CLRPL: context-aware and load balancing RPL for IoT networks under heavy and highly dynamic load. IEEE Access, 6, 23277-23291. https://doi.org/10.1109/ACCESS.2018.2817128

Ullah, R., Faheem, Y. \& Kim, B. S. (2017). Energy and congestion-aware routing metric for smart grid AMI networks in smart city. IEEE access, 5, 13799-13810. https://doi.org/10.1109/ACCESS.2017.2728623

Xiao, W., Liu, J., Jiang, N. \& Shi, H. (2014, November). An optimization of the object function for routing protocol of low-power and lossy networks. In The 2014 2nd International Conference on Systems and Informatics (ICSAI 2014) (515-519). IEEE. https://doi.org/10.1109/ICSAI.2014.7009341

Yunis, J. P. \& Dujovne, D. (2014, June). Energy efficient routing performance evaluation for LLNs using combined metrics. In 2014 IEEE Biennial Congress of Argentina (ARGENCON) (741-746). IEEE. https://doi.org/10.1109/ARGENCON.2014.6868581

\section{Copyrights}

Copyright for this article is retained by the author(s), with first publication rights granted to the journal.

This is an open-access article distributed under the terms and conditions of the Creative Commons Attribution license (http://creativecommons.org/licenses/by/4.0/). 